\title{
Genetic assignment to stock of stranded common bottlenose dolphins in southeastern Louisiana after the Deepwater Horizon oil spill
}

\author{
P. E. Rosel ${ }^{1, *}$, L. A. Wilcox ${ }^{1}$, C. Sinclair ${ }^{2}$, T. R. Speakman ${ }^{3}$, M. C. Tumlin ${ }^{4}$, J. A. Litz ${ }^{5}$, \\ E. S. Zolman ${ }^{3}$

\begin{abstract}
${ }^{1}$ National Marine Fisheries Service, Southeast Fisheries Science Center, Lafayette, LA 70506, USA
${ }^{2}$ National Marine Fisheries Service, Southeast Fisheries Science Center, Pascagoula, MS 39568, USA

${ }^{3}$ National Centers for Coastal Ocean Science, NOAA, Hollings Marine Laboratory, Charleston, SC 29412, USA

${ }^{4}$ Louisiana Department of Wildlife and Fisheries, Baton Rouge, LA 70808, USA

${ }^{5}$ National Marine Fisheries Service, Southeast Fisheries Science Center, Miami, FL 33149, USA
\end{abstract}

\begin{abstract}
Degradation of marine ecosystems is an increasing problem and extends beyond nearshore coastal waters with significant human development. However, measuring ecosystem damage and decreased ecosystem function can be difficult. Marine mammals have often been recommended as indicators for evaluating ecosystem health. Between March 2010 and July 2014, a significant cetacean unusual mortality event occurred across the northern Gulf of Mexico, where multiple demographically independent populations of common bottlenose dolphins Tursiops truncatus occur adjacent to one another. Some populations are fairly small and restricted to small habitat areas, while other populations have higher abundances and cover broader geographic ranges. An integral component to determining the impact of this event on these populations is identifying what percentage of each population the stranded animals comprise. We applied genetic assignment test methods to stranded dolphins from southeastern Louisiana to determine the proportion of dead dolphins that came from the local estuarine population versus the population found in adjacent coastal waters. Forty-one microsatellite loci were genotyped in 156 live dolphins sampled to represent the 2 potential stocks of origin and in 131 dead stranded dolphins of unknown origin. Both classical assignment tests and genetic stock identification methods indicated that approximately 6 to $7 \%$ of the sampled stranded dolphins originated from the Western Coastal Stock and the remainder from the smaller, estuarine stock in Barataria Bay, Louisiana.
\end{abstract}

KEY WORDS: Assignment test · Mixed stock analysis · Genetic stock identification · Microsatellite

\section{INTRODUCTION}

The world's oceans are experiencing significant increases in anthropogenic impacts. Historically, overfishing due to whaling (Ivashchenko \& Clapham 2014) and commercial fishing (Murawski 2010) has depleted a wide variety of taxa. More recently, impacts on the oceans are even broader, as human activities intensify and extend further offshore into deeper waters for fishing, shipping, and energy

${ }^{*}$ Corresponding author: patricia.rosel@noaa.gov exploration and extraction (Ramirez-Llodra et al. 2011, Mengerink et al. 2014). For example, bottom trawling has now extended off the continental shelf into deep, oceanic waters, where it focuses on seamounts. Trawling impacts not only the target species but also negatively impacts the benthic habitats upon which many species rely (Hiddink et al. 2011). New technologies have allowed energy exploration to expand into deeper waters and more remote areas (Copping et al. 2015). The global nature of today's

(-) Outside the USA the US Government 2017. Open Access under Creative Commons by Attribution Licence. Use, distribution and reproduction are unrestricted. Authors and original publication must be credited. 
economy has led to more shipping and to increases in the introduction of non-native species that often negatively impact the ecosystems to which they have been introduced (Briski et al. 2012). In the United States and elsewhere, coastal development and population growth have steadily increased since the 1980s (NOAA 2013), leading to increased pollutant loads, and habitat degradation and loss in coastal environments (United States Environmental Protection Agency 2012).

Measuring ecosystem damage and decreased ecosystem function can be difficult, however, and marine mammals have often been recommended as indicators for evaluating ecosystem health (Wells et al. 2004, Bossart 2011, Reif 2011). There is growing evidence of negative impacts of chemical contaminants on cetacean reproductive success (Schwacke et al. 2002), health, and immunity (Hall et al. 1992, Aguilar \& Borrell 1994, Hammond et al. 2005, Schwacke et al. 2012). Gulland \& Hall (2007) report a steady increase in the number of marine mammal mass mortality events due to exposure to harmful algal blooms over the past $40 \mathrm{yr}$. Recognition of the pathogens that cause individual marine mammal deaths is an important first step towards understanding the health status of individuals and of their ecosystem, but an important additional step is understanding the population-level impacts of such mortalities. To assess the status of a population (i.e. growing, declining, stable), one must be able to determine the number of individuals from a population impacted by a given mortality event.

In the northern Gulf of Mexico (GoM), the common bottlenose dolphin Tursiops truncatus is a widespread species, inhabiting estuarine, coastal, continental shelf and slope, and oceanic waters (Vollmer \& Rosel 2013). Currently, 36 common bottlenose dolphin stocks have been delimited in the northern GoM for management purposes under the Marine Mammal Protection Act of 1972 (Waring et al. 2015). Thirty-one of these stocks inhabit enclosed or semienclosed bays, sounds, and estuaries that line the US Gulf coast from Texas to Florida, and most are thought to have relatively low population sizes (i.e. in the low hundreds; Waring et al. 2015); however, the newest abundance estimate for the Barataria Bay Estuarine System Stock in Louisiana is near 3000 (McDonald et al. 2017, this Theme Section). In addition, there are 3 Coastal stocks inhabiting waters from the beaches or barrier islands out to the $20 \mathrm{~m}$ isobath, one Continental Shelf Stock in waters between 20 and $200 \mathrm{~m}$ deep, and one Oceanic Stock inhabiting waters $>200 \mathrm{~m}$ deep throughout US waters of the Gulf. These latter 5 stocks cover broader geographic regions and are larger than the estuarine stocks (Waring et al. 2015). The Western Coastal Stock, for example, is currently delimited in coastal waters from the Mississippi River delta to the Texas-Mexico border in the northern GoM and has an estimated abundance of 20161 (CV = 0.17) (Waring et al. 2015). Despite the more open ocean environment these coastal and shelf stocks inhabit, like common bottlenose dolphin populations in other nearshore environments, significant habitat partitioning is seen even on relatively small spatial scales (Sellas et al. 2005, Baird et al. 2009, Rosel et al. 2009, Martien et al. 2012). In the northern GoM, photoidentification studies in a variety of estuarine areas have identified long-term, year-round site fidelity (Shane 1977, Wells et al. 1987, 2017, this Theme Section, Hubard et al. 2004, Balmer et al. 2008, Bassos-Hull et al. 2013) as well as partitioning of habitat between estuarine and adjacent coastal waters (Fazioli et al. 2006). Genetic analysis of 3 estuarine populations and the adjacent coastal population off the west coast of Florida revealed significant genetic differentiation among all 4 populations (Sellas et al. 2005). In addition, genetic differentiation between these 4 populations in Florida and a population from Matagorda Bay, Texas was even higher (Sellas et al. 2005). Genetic analysis of continental shelf and oceanic waters has also revealed significant habitat partitioning even in this open water environment (Vollmer 2011). The photo-identification and genetic data in combination provide strong support for the presence of multiple, demographically distinct populations of common bottlenose dolphins that should be managed as independent stocks.

An unusual mortality event (UME) was declared for the northern GoM from the Texas-Louisiana border through the Florida Panhandle from March 2010 through July 2014 (see www.nmfs.noaa.gov/ pr/health/mmume/cetacean_gulfofmexico.htm), and $>1100$ cetaceans, primarily common bottlenose dolphins, stranded within this region, most of which (95\%) stranded dead (Litz et al. 2014). The Deepwater Horizon oil spill began in April 2010 in the northern GoM, raising questions at the time as to the role the oil spill may have played in these mortalities. Subsequent studies have indicated that the oil spill did negatively impact common bottlenose dolphin health (Schwacke et al. 2014, VennWatson et al. 2015, DWH NRDA Trustees 2016), contributing to this largest and longest-lasting UME in the northern GoM on record (Litz et al. 2014). 
An integral component of determining the impact of this mortality event on common bottlenose dolphin stocks will be identifying what percentage of each stock the stranded animals comprise. Genetic assignment methods are one way that population of origin may be identified (Manel et al. 2005), although to date, application of these methods to dolphin strandings has not been fully explored. Assignment methods can be split into 2 main types. Classical assignment tests provide a means to ascertain the source population of origin for individuals. Alternatively, one can estimate the mixture proportions for a group of individuals, identifying what proportion of the group originated from each potential source population. This latter method is commonly used for mixed stock analyses (MSA) (or genetic stock identification; GSI) for commercial fishery management, particularly for salmon management in the eastern North Pacific (e.g. Hess et al. 2014). Both methods require sampling of each potential source population of origin and sampling of the individuals that are to be assigned to their population of origin.

Here, we apply both assignment tests and GSI methods to a subset of common bottlenose dolphin strandings from the northern GoM UME to identify from which stock(s) the stranded animals originated. As described above, stock structure for T. truncatus in the northern GoM is complicated. We focus on animals recovered in the vicinity of Barataria Bay, Louisiana, where stranded dolphins have been recovered from within the bay as well as along the ocean-facing beaches of the barrier islands, including Grand Isle. Strandings in the area are most likely to have originated from either the Barataria Bay Estuarine System Stock or the Western Coastal Stock that inhabits the adjacent coastal waters out to $20 \mathrm{~m}$ depth. Modeling of carcass drift suggests stranded dolphins found on the ocean-facing beaches are unlikely to have come from the stocks inhabiting deep, offshore waters (Williams et al. 2011, L. P. Garrison pers. comm.). Furthermore, the strong site fidelity exhibited by estuarine dolphins (Shane 1977, Wells et al. 1987, Hubard et al. 2004, Balmer et al. 2008, Bassos-Hull et al. 2013) limits their movements and it is therefore also unlikely that stranded dolphins in Barataria Bay have come from adjacent estuarine stocks. The ultimate goal of this project is to provide a probability of assignment for the recovered stranded animals to either the Western Coastal Stock or the Barataria Bay Estuarine System Stock to better quantify the numbers of mortalities per stock for purposes of injury and stock assessment. These mortalities will represent an underesti- mate of the true number of mortalities, as not every dead dolphin makes it to shore or is found and reported (see Peltier et al. 2012).

\section{MATERIALS AND METHODS}

\section{Sampling, DNA extraction, microsatellite genotyping}

Assignment test methods require 2 sets of samples: one set, often referred to as the baseline, consists of samples representative of the potential source populations; the second set contains the unknown samples to be assigned to source populations. For the baseline samples to represent the Barataria Bay Estuarine System Stock of Tursiops truncatus, skin biopsies ( $\mathrm{n}=$ 79) were collected from free-ranging animals in Barataria Bay via remote biopsy methods (Gorgone et al. 2008, Sinclair et al. 2015) in 2010-2012, and skin tissue samples $(n=55)$ were collected from dolphins captured during capture-release health assessment studies (see Schwacke et al. 2014) in 2011 and 2013 in Barataria Bay (Fig. 1A). In addition, 30 skin biopsies were collected from free-ranging dolphins in coastal waters outside Barataria Bay to represent the adjacent Western Coastal Stock (Fig. 1A). The coastal biopsies were collected in summer 2013 in waters $>2 \mathrm{~km}$ from shore to minimize the chance of sampling estuarine dolphins. The stranded samples of unknown origin $(\mathrm{n}=136)$ were collected from dolphins recovered between 2010 and 2013 from coastal and estuarine waters in the Barataria Bay area (Fig. 1B). DNA was extracted from all samples using a Qiagen DNeasy Tissue \& Blood extraction kit following the manufacturer's protocols. Extracted DNA was quantified (DyNA Quant 200, GE Healthcare Life Sciences) and DNA quality was examined via gel electrophoresis.

Samples were first genotyped at 19 microsatellite loci (Ttr04, Ttr11, Ttr19, Ttr34, Ttr48, Ttr58, Ttr63, TtrFF6 [Rosel et al. 2005]; MK5, MK6, MK8, MK9 [Krützen et al. 2001]; TexVet5, TexVet7 [Rooney et al. 1999]; KWM12a [Hoelzel et al. 1998]; PPHO130 [Rosel et al. 1999]; and EV14, EV37 [Valsecchi \& Amos 1996], and EV94 [modified from Valsecchi \& Amos 1996]) following Vollmer (2011) (for PCR conditions, see Table S1 in the Supplement at www. int-res.com/articles/suppl/n033p221_supp.pdf). When necessary to enhance amplification, 0.08-0.24 mg $\mathrm{ml}^{-1}$ bovine serum albumin was added to the PCR reaction. Genotyping was performed on an ABI 3130 Genetic Analyzer with GeneScan ${ }^{\mathrm{TM}} 500$ LIZ $^{\circledR}$ as an 

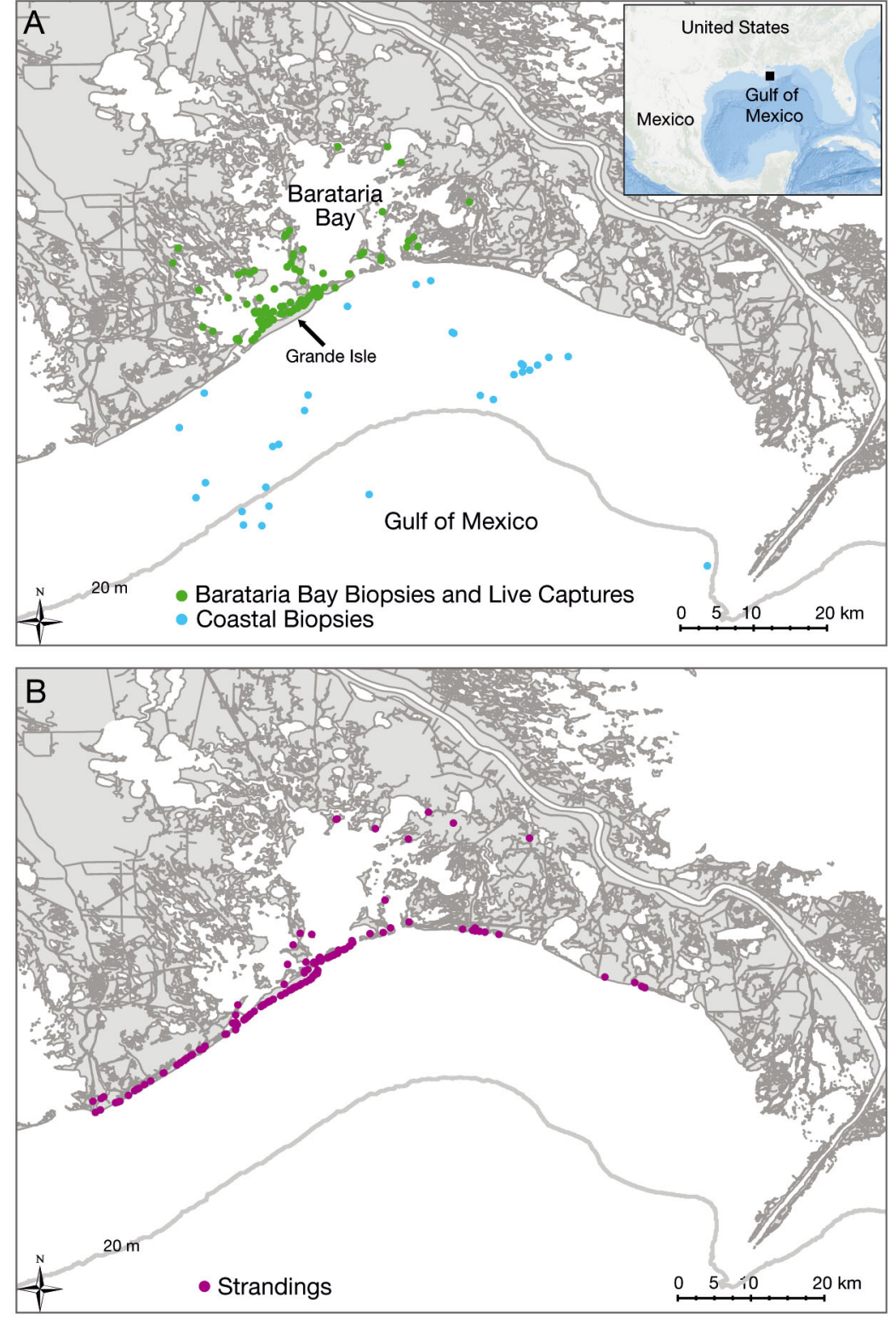

Fig. 1. Common bottlenose dolphin (Tursiops truncatus) sampling locations. (A) Barataria Bay and Coastal biopsy and capture-release samples used in baseline (inset: Gulf of Mexico). (B) Samples from stranded animals. The $20 \mathrm{~m}$ isobath is shown

internal size standard. Allele sizes were determined using GeneMapper v.4.1 (ABI). The probabilities of identity, $\mathrm{P}_{\mathrm{ID}}$ and $\mathrm{P}_{\mathrm{ID}(\mathrm{sib})}$ (Waits et al. 2001), were estimated using GenAlEx v.6 (Peakall \& Smouse 2006), and were used to identify the probability of finding the same multilocus genotype at random within the population. $\mathrm{P}_{\mathrm{ID}(\mathrm{sib})}$ provides a more conservative estimator and is useful for circumstances when there may be population substructure or in small populations where related individuals may remain in prox- imity and be sampled (Waits et al. 2001). Data for these 19 loci were used in MSTools (Park 2001) to determine whether any live dolphins had been inadvertently sampled more than once. One member of each duplicate (see 'Results') was removed from all subsequent data collection and analyses. The 136 stranded animals were also genotyped at these first 19 loci and MSTools was similarly used to search for duplicates between stranded animals and biopsy samples.

The power to detect differentiation and the accuracy of assignment tests are both directly related to the number of informative loci. To improve assignment tests results, we screened an additional 66 microsatellite loci and ultimately identified and optimized an additional 22 loci, 14 identified from screening the common bottlenose dolphin genome through Illumina 454 sequencing (see Lance et al. 2013) and 8 optimized from loci previously identified in other cetacean species. See Text S1 in the Supplement for description of methods to identify and optimize these additional loci. All samples (baseline and strandings) were then genotyped at the 22 new microsatellite loci using a Qiagen Type-it Microsatellite PCR kit (see Table S2 in the Supplement for PCR conditions). Quality control procedures were applied for all microsatellite genotyping: all PCR reactions contained a no-DNA control as well as a positive DNA control that was used to ensure consistency across PCR amplification and genotyping runs. In addition, $8.7 \%$ of the biopsy/ capture-release samples were re-genotyped at 19 loci to examine genotyping error rate.

Microchecker v.2.2.3 (Van Oosterhout et al. 2004) was used to test each locus in the coastal biopsy sample set and the Barataria Bay biopsy/capture-release sample set for the presence of genotyping errors due to null alleles, allelic dropout, and incorrect scoring of stutter. We also tested for significant departure from Hardy-Weinberg equilibrium (HWE) proportions following Guo \& Thompson (1992), and linkage 
disequilibrium was measured using Fisher's exact tests. Both tests were performed on the full data sets from Barataria Bay $(\mathrm{n}=127)$ and coastal waters $(\mathrm{n}=$ 29) and also for the baseline populations identified by STRUCTURE (see next subsection: Barataria Bay estuarine [BBe]: $n=49$, Barataria Bay island [BBi]: $n=67$, Coastal: $\mathrm{n}=24$ ) using GENEPOP v.4.0.10 (Rousset 2008) and 10000 dememorizations, 1000 batches, and 10000 iterations per batch. The level of significance was corrected for multiple tests using the sequential Bonferroni technique (Holm 1979). Similarly, we estimated observed and expected heterozygosities, the number of alleles per locus, and the levels of genetic differentiation among populations for both the full data sets and the populations identified by StRUCtURE using the Weir \& Cockerham (1984) measure, $F_{\mathrm{ST}}$, using Arlequin v.3.5 (Excoffier \& Lischer 2010).

\section{Identifying baseline populations}

Assignment methods require that potential source populations be sampled such that microsatellite allele frequencies for each source population are well characterized. Thus, the sample set used to represent each source population should be representative of each population and should not contain samples from individuals that are not members of the population, i.e. each baseline sample should be a 'pure' sample of each potential source population to be tested (Manel et al. 2005). For the baseline sample of the Western Coastal Stock, we used the skin biopsy samples collected in coastal waters $>2 \mathrm{~km}$ from shore. The baseline sample for the Barataria Bay Estuarine System Stock is more difficult to identify because, while Barataria Bay is delimited for management purposes as containing a single common bottlenose dolphin stock, other large bays and estuarine systems are thought to contain multiple dolphin communities (e.g. Urian et al. 2009), and Barataria Bay has been little examined. Therefore, our first step was to test for evidence of population structure within Barataria Bay so that the appropriate baseline sample set for the assignment methods could be identified.

The Bayesian clustering program STRUCTURE (Pritchard et al. 2000) was therefore used to test for evidence of multiple genetic clusters among the biopsy and capture-release samples collected in Barataria Bay. StRucture groups individuals into clusters (K) without use of a priori information on where individuals come from. Correlated allele frequency and admixture models were applied to 10 independent runs of $\mathrm{K}=1-5$ using 500000 iterations and a burn-in of 100000 . The mean ln probability of the data (X) given the number of cluster $(\mathrm{K})[\ln \operatorname{Pr}(\mathrm{X} \mid \mathrm{K})]$, across the 10 runs was examined to identify the best number of populations given the data and were compared to the $\Delta \mathrm{K}$ method of Evanno et al. (2005). Correlating cluster membership with geographic sampling location allows exploration of whether the STRUCTURE results are biologically meaningful (Pritchard et al. 2009). Therefore, we plotted (ArcGIS 10.3) geographic sampling location for each sample based on cluster membership (q-values). We explored 2 qvalue thresholds to assign membership: a more stringent value of $q \geq 0.8$, and a more lenient value of $q \geq$ 0.6. To further look for biological support for the clusters identified by STRUCTURE, we compared general habitat preference patterns for 29 animals in the data set that had been fitted with satellite telemetry tags during the 2011 and 2013 Barataria Bay health assessments (Schwacke et al. 2014). Finally, we reran STRUCTURE as above, incorporating the coastal biopsy samples, to determine whether any estuarine dolphins had been biopsied in waters $>2 \mathrm{~km}$ from shore in order to ensure our coastal baseline sample set did not contain any estuarine dolphins.

The STRUCTURE analysis provided strongest support for the existence of 2 genetic clusters within Barataria Bay (see 'Results'). Therefore, 2 versions of a 3baseline population model (BBe, $\mathrm{BBi}$, and Coastal) were analyzed by assignment tests. The first data set was created using the q-value cut-off of 0.6 to create the 2 Barataria Bay baselines, and the second data set created using the q-value cut-off of 0.8 to create the 2 Barataria Bay baselines. The Coastal baseline population was created using a q-value cut-off of 0.8 in both cases.

\section{Assignment methods}

Once the baseline sample set for the Barataria Bay Estuarine System and Coastal stocks was identified, we used ONCOR (Kalinowski et al. 2007) and GeneClass2 (Piry 2004) to perform assignment tests to identify population of origin for stranded samples from the Barataria Bay area. First, we assessed the ability of the baseline data set to correctly assign individual dolphins to their population of origin. We used the leave-one-out and individual assignment options in ONCOR and applied ONCOR to the full baseline data set. ONCOR uses a jackknife procedure that removes an individual from the data set and then uses a maximum likelihood algorithm to 
estimate the probability that the individual came from each of the baseline samples. After running each individual, the software calculates the number of correct assignments for each population. We also used ONCOR to examine the performance of the baseline data sets and how accurate the mixture analysis is likely to be. We performed $100 \%$ simulations (assuming the mixed stock all comes from 1 population in the baseline). Here, the software simulates a mixture sample in which all the baseline individuals are from the same population and then uses maximum likelihood methods to estimate the percentage of the mixture correctly assigned to the population of origin. Simulations involved a cross-validation method as discussed by Anderson et al. (2008). We performed 1000 simulations, sampled 200 individuals, and used the empirical baseline sample sizes. Seeb et al. $(2000,2007)$ recommended that at least $90 \%$ correct assignment is necessary to have confidence in the MSA.

We next used the probability of exclusion test in GeneClass2 to identify any stranded animal that may have originated from outside of the 3 sampled baseline populations (Cornuet 1999, Manel et al. 2005). GeneClass2 uses a Bayesian approach and the method of Rannala \& Mountain (1997) to estimate population allele frequencies. To test whether any of our identified baseline populations could be ruled out as population of origin for individuals, Monte Carlo resampling was performed in GeneClass2 using an assignment threshold of 0.01 and following the algorithm of Paetkau et al. (2004) with 10000 simulated individuals.

ONCOR was then used to perform individual assignments of the stranded dolphins to determine their most likely source population. ONCOR assigns an individual to the baseline population that has the highest probability of producing the individual's genotype in the mixture. ONCOR uses both mixture proportions and genotype frequencies to estimate population of origin, uses a conditional maximum likelihood approach, and implements the method of Rannala \& Mountain (1997) to estimate baseline allele frequency distributions when estimating assignment probabilities.

Finally, we used ONCOR to examine the overall stock composition of the stranded animals using the MSA framework. In contrast to the individual assignment method, MSA is a population-level method that estimates the relative contributions of each baseline population to the mixture sample. Confidence intervals around the mixture proportions were estimated using 1000 bootstrap replicates.

\section{RESULTS}

\section{Genotyping}

DNA was extracted from a total of 164 biopsy and capture-release samples from the source populations. Of these, 3 individuals from Barataria Bay had extremely low DNA quantity/quality and were dropped from further analysis. After genotyping at the first 19 microsatellite loci, 5 pairs of samples were identified as duplicates using MSTools: 4 pairs amongst the Barataria Bay samples and 1 pair from the coastal biopsies. Probabilities of identity $\left(\mathrm{P}_{\mathrm{ID}}=8.8\right.$ $\times 10^{-17} ; \mathrm{P}_{\mathrm{ID}(\mathrm{sib})}=5.8 \times 10^{-7}$ ) were sufficiently low to suggest these represent true duplicates rather than different animals sharing the same genotype by chance. Each pair had an identical genotype across all 19 loci and also had the same mtDNA control region haplotype and same sex. One member of each duplicate pair was removed from all subsequent data collection and analyses. The remaining 156 samples were successfully genotyped at the additional 22 microsatellite loci, except for 1 sample that did not amplify for locus KWM9b. After genotyping the 136 stranded animals at the first 19 loci, we also identified 5 stranded animals that were duplicates of dolphins that had been previously sampled within Barataria Bay when alive (i.e. previously biopsied or sampled during the health assessments). These 5 dolphins were removed from the data set, leaving 131 individuals to assign to stock.

No evidence for genotyping errors was detected using Microchecker. No incorrect genotypes were found after repeat genotyping of 14 samples $(8.7 \%$ of the biopsy/capture-release samples), and 5 dolphins unknowingly sampled twice also had no evidence of genotyping error. No loci were out of HWE or showed evidence for linkage disequilibrium after Bonferroni correction (see Tables S3 \& S4 in the Supplement at www.int-res.com/articles/suppl/n033 p221_supp.pdf).

\section{Identifying baseline samples}

The STRUCTURE analysis of samples collected in Barataria Bay indicated that $\mathrm{K}=2$ was best, with $\mathrm{K}=$ 3 close behind (Fig. S1A in the Supplement). For K = 2 and both q-cutoff values, geographic partitioning was evident for the 2 clusters (Fig. 2A), one cluster concentrated in estuarine waters of the western side of Barataria Bay and the other concentrated in estuarine waters of the eastern side, with members of 

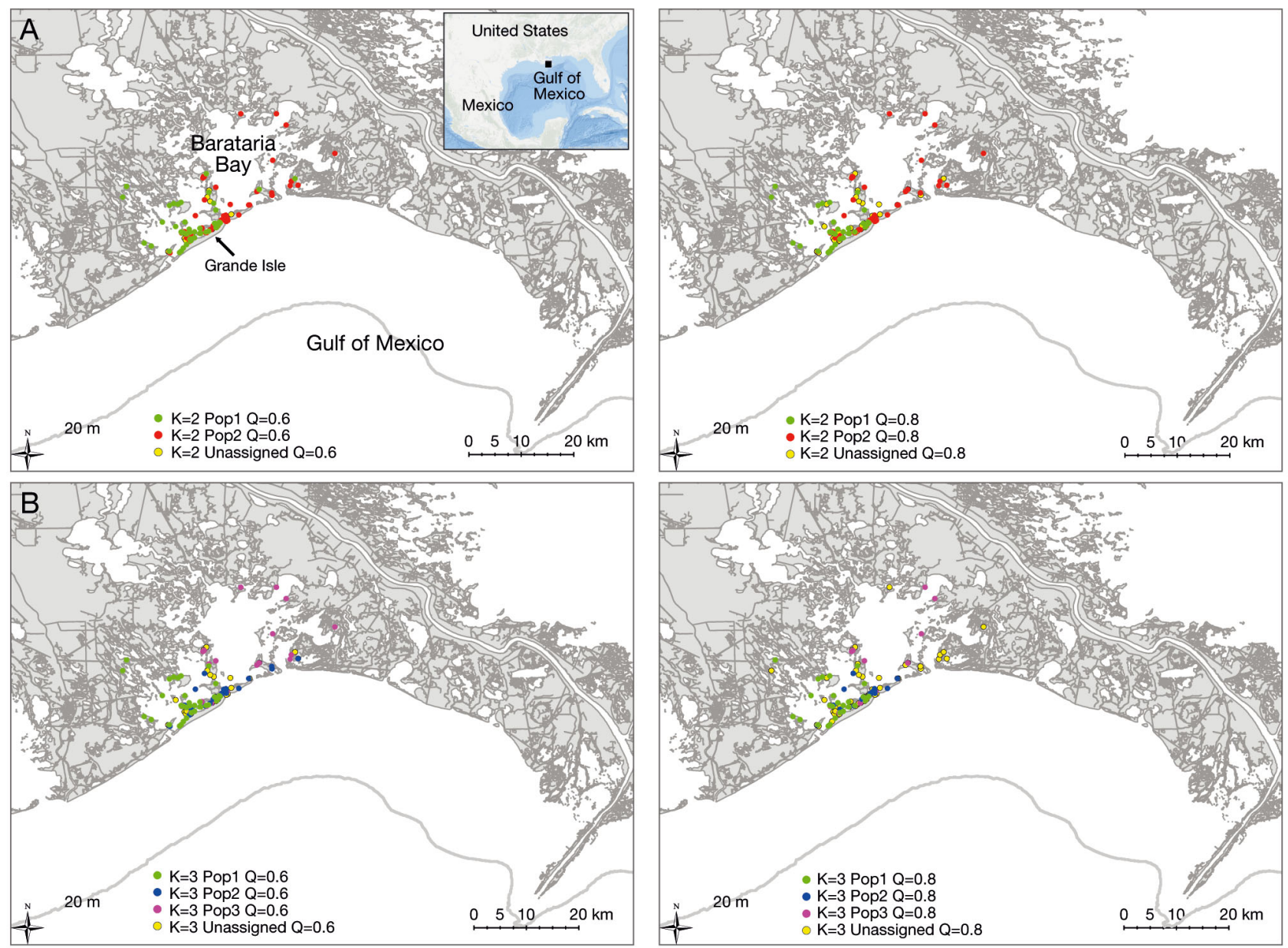

Fig. 2. Geographic sampling location of dolphins Tursiops truncatus used in STRUCTURE runs using Barataria Bay biopsy and capture-release samples only. Samples color-coded for (A) $\mathrm{K}=2$ STRUCTURE clusters and (B) $\mathrm{K}=3$ STRUCTURE clusters and a $\mathrm{q}$-value cutoff of $\mathrm{q} \geq 0.6$ (left panels) or $\mathrm{q} \geq 0.8$ (right panels) for identifying clusters. K: number of clusters, $\mathrm{q}$-value: probability of cluster membership. The $20 \mathrm{~m}$ isobath is shown

both clusters utilizing waters directly north of the larger barrier island of Grand Isle. At $\mathrm{K}=3$, the $\mathrm{K}=2$ cluster associated with the more eastern estuarine waters was split into dolphins associated primarily with the barrier islands and a second cluster found predominantly in estuarine waters in the northern and eastern part of the bay (Fig. 2B). Dolphins associated with estuarine waters of the western part of the bay and barrier island remained as in the $\mathrm{K}=2$ result.

For the purposes of the assignment tests, in which our goal was to examine the relative contribution of Barataria Bay Estuarine System versus Coastal stock dolphins to strandings in the Barataria Bay area, we chose to use the $\mathrm{K}=2$ result of the STRUCtURE runs and the $q \geq 0.6$ threshold for Barataria Bay to create the baseline sample set of Barataria Bay. Overall, $\mathrm{K}=$ 2 exhibited the smallest $\ln \operatorname{Pr}(\mathrm{X} \mid \mathrm{K})$, and it is recommended to accept the 'smallest value of $\mathrm{K}$ that cap- tures the major structure in the data' (Pritchard et al. 2009), and it had the highest $\Delta \mathrm{K}$. Furthermore, the number of samples that were unclustered at $\mathrm{K}=3$ was higher than at $\mathrm{K}=2$ (number of unassigned individuals at $K=2$ was 11 and 36 for the $q \geq 0.6$ and $q \geq$ 0.8 cut-offs, respectively; at $K=3$, it was 28 and 65 for the $\mathrm{q} \geq 0.6$ and $\mathrm{q} \geq 0.8$ cut-offs, respectively). This higher number of individuals unassigned at both qvalue cutoffs for the $K=3$ clusters suggests that the data show stronger support for $K=2$ over $K=3$. In addition, the difference between $K=2$ and $K=3$ primarily reflects a division of dolphins within Barataria Bay rather than between the Barataria Bay Estuarine System and Coastal stocks, the latter being the primary focus of the analysis. Finally, tag-telemetry data (Wells et al. 2017) also supported population structure within Barataria Bay (see 'Discussion'). These tracking data provide an independent line of evidence in 
Table 1. Microsatellite $F_{\mathrm{ST}}$ values (and sample sizes of Tursiops truncatus) for pairwise comparisons of the baseline populations used within Barataria Bay (using $q \geq 0.6$ and $q \geq$ 0.8 cut-off values) and the Coastal population. The Coastal baseline samples were identified using a $q \geq 0.8$ cut-off value. $F_{\mathrm{ST}}$ values below diagonal, associated $p$-values above diagonal. BBe: Barataria Bay estuarine, BBi: Barataria Bay island, q-value: probability of cluster membership

\begin{tabular}{|lrcc|}
\hline & BBe & BBi & Coastal \\
\hline $\mathbf{q} \geq \mathbf{0 . 6}$ & & & \\
$\mathrm{BBe}(\mathrm{n}=49)$ & & 0.00 & 0.00 \\
$\mathrm{BBi}(\mathrm{n}=67)$ & 0.0276 & & 0.00 \\
Coastal $(\mathrm{n}=24)$ & 0.0474 & 0.0229 & \\
Overall $F_{\mathrm{ST}}=0.0302, \mathrm{p}<0.001$ & & \\
$\mathbf{q} \geq \mathbf{0 . 8}$ & & & \\
$\mathrm{BBe}(\mathrm{n}=34)$ & $0.00 \pm 0.00$ & 0.00 \\
$\mathrm{BBi}(\mathrm{n}=57)$ & 0.0384 & & 0.00 \\
Coastal $(\mathrm{n}=24)$ & 0.0534 & 0.0239 & \\
Overall $F_{\mathrm{ST}}=0.0366, \mathrm{p}<0.001$ & & \\
\hline
\end{tabular}

support of the genetic clusters identified by STRUCTURE. The final sample sizes were $n=49$ for the BBe baseline comprising samples primarily from the western estuarine waters, and $n=67$ for the BBi baseline comprising samples mainly associated with the barrier islands but also some within the eastern estuarine waters of the bay. In total, the number of baseline samples used to represent Barataria Bay was 116. The $F_{\mathrm{ST}}$ estimate between samples representing the Western Coastal Stock $(n=29)$ and the full Barataria Bay data set $(\mathrm{n}=127)$ was $0.021(\mathrm{p} \leq 0.0001) . F_{\mathrm{ST}}$ between the BBe and BBi baseline samples was significant $\left(F_{\mathrm{ST}}\right.$ $=0.028$ and $0.038, p \leq 0.0001$, for the $q \geq 0.6$ and $q \geq$ 0.8 cut-offs, respectively; Table 1). Pooling the BBe and BBi samples and comparing them to the Coastal population returned $F_{\mathrm{ST}}=0.027$ and $0.026(\mathrm{p} \leq 0.0001)$ for the $q \geq 0.6$ and $q \geq 0.8$ cut-offs, respectively. The highest $F_{\mathrm{ST}}$ value was seen between $\mathrm{BBe}$ and the Coastal population $\left(F_{\mathrm{ST}}=0.05, \mathrm{p} \leq 0.0001\right)$.

We also used STRUCTURE, as above, with all nonstranding samples (e.g. all Barataria Bay samples plus the Coastal biopsies) to examine whether any Barataria Bay dolphins were sampled during the coastal biopsy effort. Mean $\operatorname{Pr}(\mathrm{X} \mid \mathrm{K})$ values were very close for $K=2$ and $K=3$ (Fig. S1B in the Supplement). At $K=2$, the samples were generally split into those collected in coastal waters $>2 \mathrm{~km}$ from shore and those collected in Barataria Bay (Fig. 3A). At $K=3$, the Coastal cluster remained the same while the Barataria Bay samples were split into 2 clusters similar to the pattern seen when Barataria Bay samples were used alone in Structure (Fig. 3B). At $\mathrm{K}=2,24$ of the 29 coastal biopsy samples were in 1 cluster using a q-value cut-off $\geq 0.8$. The average q-value for those 24 samples was 0.913 . The remaining 5 coastal biopsies were unassigned, i.e. they did not group in the Barataria Bay cluster either. Lowering the stringency to q-values $\geq 0.6$ allowed 3 of the unassigned coastal biopsies to be placed in the Coastal cluster. The average q-value for the Coastal cluster using a $q \geq 0.6$ cutoff was 0.852 . There were a few Barataria Bay samples that clustered with the coastal biopsies at $\mathrm{K}=2$, though most of these became unclustered at $\mathrm{K}=3$. These samples, when run in the Barataria-Bayonly STRUCTURE runs described above, all fell into the island-associated clusters. Several of these animals had satellite tags and none went offshore more than 2 to $4 \mathrm{~km}$ (Wells et al. 2017), illustrating that they remain around the barrier islands and do not venture into waters occupied by the Western Coastal Stock. Thus, they were retained in the BBi data set, and the final Coastal baseline sample contained 24 samples assigned using the STRUCTURE q-value cutoff of $\geq 0.8$.

\section{Assignment of strandings}

Self-assignment tests using ONCOR and the baseline sample set proved effective at assigning baseline samples to their population of origin. The BBe and $\mathrm{BBi}$ individuals returned the best result, with $98 \%$ and $97 \%$ correctly assigned, respectively. The selfassignment for the Coastal population was biased downwards, with $83 \%$ correctly assigned. These results indicate that the baseline data set has sufficient power to perform assignment tests, though assignments to the Coastal population may be somewhat underestimated.

Using the 3-baseline population scenario derived from the less stringent q-value in Barataria Bay and a threshold of 0.05, GeneClass2 excluded 2 stranded animals from all 3 potential source populations. Therefore, the final sample size for use in estimating assignment probabilities in ONCOR dropped to 129. ONCOR assigned 9 stranded animals to BBe (assignment probability range: $0.66-1.0$, mean: 0.92$), 8$ to the Coastal population (0.63-0.99, mean: 0.82$)$, and 111 to the BBi population (0.66-1.0, mean: 0.98). One individual was assigned nearly equally to the $\mathrm{BBi}$ and the Coastal populations.

\section{MSA}

The $100 \%$ simulation test for the MSA ranged from $92.7 \%$ for the Coastal population to $99.6 \%$ for the 

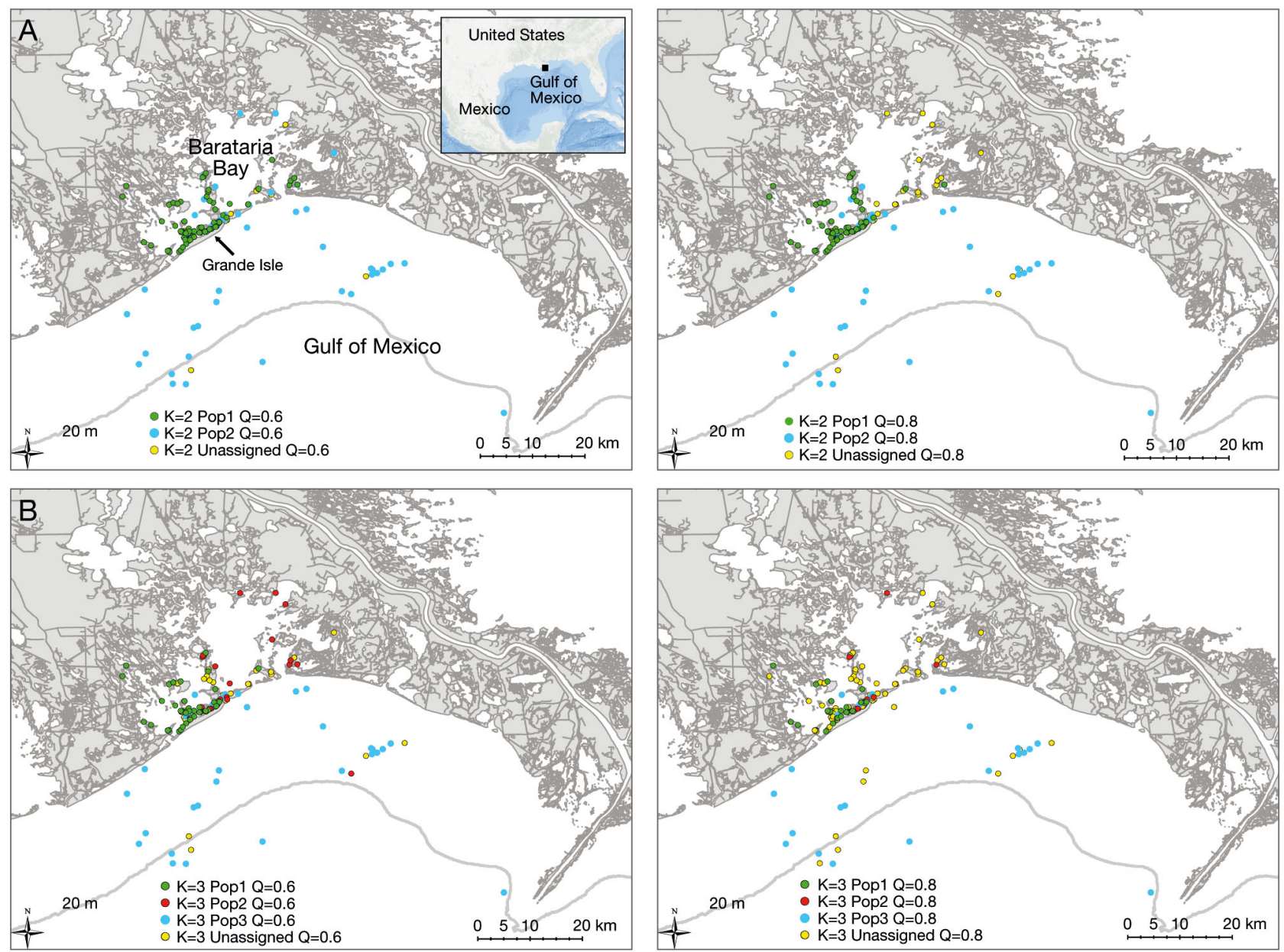

Fig. 3. Geographic sampling location of dolphins Tursiops truncatus used in STRUCTURE runs using Barataria Bay plus Coastal biopsy samples together. Samples color-coded for (A) $K=2$ Structure clusters and (B) $K=3$ Structure clusters and a q-value cutoff of $q \geq 0.6$ (left panels) or $q \geq 0.8$ (right panels) for identifying clusters. K: number of clusters, $q$-value: probability of cluster membership. The $20 \mathrm{~m}$ isobath is shown

estuarine populations, all above the $90 \%$ threshold recommended for confidence in the mixture analysis. Analysis of mixture proportions for the stranded samples using the 3-population scenario returned proportions of $6.69 \%$ Coastal (95\% CI: $0.010-0.153)$ and 93.31\% Barataria Bay (summing BBe and BBi).

\section{DISCUSSION}

Fully understanding the impacts of mortality events on wild populations is critical for accurate assessment of the population-level impacts of such events. In cases where multiple populations exist in close proximity and a mortality event is broadly distributed, it can be difficult to identify the population of origin of carcasses. The 2010-2014 cetacean UME in the northern GoM provides an excellent example of just such a case. More than 1100 cetaceans, primarily common bottlenose dolphins, died during this event (Litz et al. 2014). Gulf-wide, the number of possible source populations for these strandings is quite high and includes many small, genetically distinct estuarine populations. Here we tested molecular genetic assignment methods and their ability to identify the population source of dead stranded common bottlenose dolphins recovered in the Barataria Bay region of southeastern Louisiana during this UME. By focusing on strandings in this region, we were able to sample the most likely source populations. If successful, assignment tests could be an additional tool for investigating and assessing population-level impacts of marine mammal UMEs.

Genetic assignment tests can be sensitive to incomplete sampling of baseline populations as well as baseline populations composed of individuals from 
multiple populations (Manel et al. 2005). Because common bottlenose dolphins often exhibit population structure on very fine scales (Sellas et al. 2005, Rosel et al. 2009), we examined whether population structure might exist within Barataria Bay prior to performing assignment tests. Although the microsatellite data did not show evidence of a Wahlund effect, i.e. only 1 locus, DL12, had a HWE p-value $<0.05$, or significant linkage disequilibrium, STRUCTURE analysis suggested the presence of 2 or even 3 unique genetic clusters or populations within Barataria Bay (Fig. 2A,B). These groups are geographically partitioned; one is found primarily around the barrier islands and the other 2 utilize more estuarine habitat in the western and eastern portions of Barataria Bay, suggesting some biological meaning to the clusters. The test for HWE is a weak test (Waples 2015), so it is not surprising that it did not provide strong evidence for a mixed sample within Barataria Bay, though DL12 was no longer out of HWE when the samples were split into $\mathrm{BBi}$ and $\mathrm{BBe}$. The genetic results are well supported by tag-telemetry data for 29 dolphins in Barataria Bay (Wells et al. 2017) that were also in the genetic data set. The movement data indicated the tagged dolphins stayed within the bay yearround and across years in some cases. Examination of habitat usage of the satellite-tagged dolphins revealed that most of the tagged animals utilized habitats in line with the genetic pattern of westernestuarine-associated, island-associated, and easternestuarine-associated dolphins (Wells et al. 2017) as identified in the $K=3$ StRUCtURE results for the Barataria Bay samples. Overall, the genetic data and the movement-based home-range data combined provide strong evidence for the presence of discrete groups within Barataria Bay that are also distinct from the dolphins that inhabit the nearshore coastal waters beyond the bay. The level of genetic differentiation seen among these groups was significant (Table 1) and in line with levels of differentiation measured among other recognized dolphin stocks in the eastern United States. Additional sampling within Barataria Bay will further our understanding of these discrete dolphin groups.

Results from the assignment tests indicated that most of the stranded animals analyzed came from the Barataria Bay Estuarine System Stock, while approximately $6-7 \%$ originated from the adjacent Western Coastal Stock. Both the straight assignment tests and the mixture analysis returned similar values for the proportion of Western Coastal Stock dolphins present in the strandings (assignment tests: 6.2\%, MSA: $6.7 \%$ ). Furthermore, the majority of the carcasses assigned to the Barataria Bay Estuarine System Stock originated from the barrier island-associated dolphins rather than from dolphins whose home ranges included primarily the more estuarine and marshgrass dominated portions of Barataria Bay. This difference in the number of stranded dolphins assigned to the estuarine versus island-associated dolphins of Barataria Bay may result from biological and/or methodological factors. The island-associated dolphins could truly be more impacted by this UME and therefore make up a higher percentage of carcasses. Alternatively, all subpopulations within Barataria Bay may be equally impacted by the event, but observing and retrieving carcasses from the large and complex marsh habitat utilized by the more estuarine-associated dolphins could result in fewer estuarine-associated dolphin carcasses being discovered and therefore fewer available for assignment. These 2 hypotheses are not mutually exclusive and a combination of the two is plausible.

The lower percentage of carcasses recovered from the Western Coastal Stock is in line with previous studies of cetacean carcass recovery rates. Peltier et al. (2012) tagged 100 bycaught short-beaked common dolphin (Delphinus delphis) and harbor porpoise (Phocoena phocoena) carcasses and released them on average $41 \pm 31.5 \mathrm{~km}$ offshore of the French Atlantic coast. Of these, $8 \%$ were recovered, although modeling experiments suggested that a far higher proportion (62\%) of bycaught carcasses should have stranded. Williams et al. (2011) used the ratio of annual strandings to total number of expected mortalities based on abundance estimates and mortality rates to estimate a $2 \%$ recovery rate for strandings of primarily deep-water, offshore cetacean species in the northern GoM. Our estimate that 6-7 \% of recovered Tursiops truncatus carcasses from the Barataria Bay area come from coastal waters is a slightly different kind of estimate, but is nevertheless in the same order of magnitude as these previous studies. Members of the Western Coastal Stock of $T$. truncatus are delimited to inhabit waters from the coastline out to the $20 \mathrm{~m}$ isobath, which, in the waters off Barataria Bay, stretches out to approximately $17 \mathrm{~km}$ from shore. Prevailing surface winds based on a climatological average over the period 1991-2010 are from the south in summer and the southeast in all other seasons (Crouch \& Shein 2011) and should push floating carcasses shoreward. Surface currents, however, are directed more to the west (Zavala Hidalgo et al. 2003), and so it is possible that carcasses from dolphins inhabiting coastal waters off Barataria Bay would be pushed further west beyond 
our study area. Furthermore, with the long peninsula of the Mississippi Delta jutting south just east of the area we sampled, the source for Coastal Stock carcasses drifting in from the east seems limited.

In addition to the uncertainty in the percentage of Western Coastal Stock carcasses that would make it to the beaches, the genetic analysis performed here may also impart a downward-biased estimate of coastal assignments. The sample size for the Western Coastal Stock baseline sample was relatively small. Population allele frequency estimates may therefore not be as robust as is desirable for assignment tests. This possibility is borne out in the selfassignment tests performed in ONCOR. While 97 and $98 \%$ of the estuarine and island-associated dolphins, respectively, in the baseline samples were correctly assigned to their population of origin, this value was $83 \%$ for the Western Coastal Stock baseline sample. Seeb et al. $(2000,2007)$ suggested that mean correct assignments of $\geq 90 \%$ indicate highly identifiable groups, so confidence in the Barataria baseline samples is high. The lower value for the Western Coastal Stock baseline sample suggests that assignment confidence is still adequate but the baseline sample may not have been thoroughly sampled. The smaller sample size for the Western Coastal Stock baseline would bear that out. In addition, the degree of genetic divergence detected between the coastal and island-associated populations is relatively low $\left(F_{\mathrm{ST}}=0.023\right)$. Individual assignment test methods are more accurate with increasing divergence levels (Araujo et al. 2014), though good assignment accuracy has been regularly reported for $F_{\mathrm{ST}}$ values as low as 0.01 (Araujo et al. 2014). The relatively low divergence, coupled with the small baseline sample for the Western Coastal Stock, may result in some coastal animals having been assigned to the island-associated Barataria Bay population. Use of the MSA option in ONCOR should help minimize some of this bias, however. Use of mixture models integrates all the information available in the baseline as well as in the mixture sample, and, since they do not require estimating assignments for each individual in the mixture, they do not carry with them the uncertainty and error inherent in each of those assignments, resulting in improved performance over classical assignment tests (Koljonen et al. 2005, Manel et al. 2005, Moran et al. 2014). Moreover, they are less prone to overestimating assignment power (Anderson et al. 2008, Anderson 2010). Interestingly, for our system, both methods produced similar values - the Western Coastal Stock contributed 6-7\% of the stranded animals we analyzed. Finally, as mentioned in 'Results', GeneClass2 excluded 2 strandings in the first step of the assignment analysis. These animals may have come from an unsampled baseline population, for example the Continental Shelf Stock of common bottlenose dolphins found further offshore. Alternatively, they may have originated from the Western Coastal Stock, but their alleles may not have been well represented in the Western Coastal Stock baseline, given its smaller size, and were therefore excluded.

It is important to recognize that the number of carcasses we have assigned to the 2 stocks is not an estimate of the total number of animals that have died from each stock during the time of the UME, only the number that we analyzed. The number of stranded dolphins available for analysis is a function of multiple biological and physical factors, including abundance and mortality rates of each stock, carcass buoyancy or sinking rate, size, and decomposition rate, scavenging rate, distance from shore at time of death, drift rates, wind and current direction and strength (see Peltier et al. 2012 for a full discussion, Wells et al. 2015). Additionally, carcass detection rates, which are influenced by the level of search effort and the complexity of the habitat and ease with which carcasses can be detected, can influence the number of stranded samples available for analysis. Finally, for this study, only carcasses that yielded DNA of sufficient quality for genotyping were included in the analysis. Nevertheless, knowledge of the relative ratio of strandings of estuarine to coastal dolphins can be used in a larger modeling framework to estimate total dolphin mortality during this UME (Thomas et al. 2017, this Theme Section). Overall, the genetic assignment test method showed significant promise for assessing impacts of mortality events on dolphin populations. Keys to success for future events include a good understanding of population structure for, and adequate and appropriate sampling of, the potential source populations that may be represented in the recovered mortalities, and a robust and timely stranding response effort.

Acknowledgements. We thank the biopsy and capturerelease field crews and volunteers who were involved in collecting samples and Louisiana marine mammal stranding network members involved in carcass recovery and sampling, particularly the Louisiana Department of Wildlife and Fisheries, including the Fisheries Research Lab Staff, and staff from the Audubon Nature Institute, including Suzanne Smith, who obtained samples from carcasses during necropsy. Additionally, we thank NMFS Southeast Fisheries Science Center stranding program staff, including Blair 
Mase-Guthrie, Elizabeth Stratton, and Lauren Noble, and Erin Fougeres of the Southeast Regional Office, all of whom coordinated the stranding response and sample collection during the unusual mortality event. The analysis was significantly improved through discussion and suggestions from Robin Waples, NMFS Northwest Fisheries Science Center, and comments from 2 anonymous reviewers. Samples were collected under NMFS MMPA permit nos. 779-1633 and 932-1905/MA-009526. Response to cetacean stranding events is conducted by Marine Mammal Stranding Networks (MMSN) authorized under Section 112c (Stranding Agreements from the NMFS regional offices) or Section $109 \mathrm{~h}$ (Federal, State, or local government officials) of the Marine Mammal Protection Act. This work was part of the DWH NRDA being conducted cooperatively among NOAA, other federal and state Trustees, and BP PLC. The findings and conclusions in this paper are those of the authors and do not necessarily represent the view of NOAA or of any other natural resource Trustee for the BP/Deepwater Horizon NRDA.

\section{LITERATURE CITED}

Aguilar A, Borrell A (1994) Abnormally high polychlorinated biphenyl levels in striped dolphins (Stenella coeruleoalba) affected by the 1990-1992 Mediterranean epizootic. Sci Total Environ 154:237-247

Anderson EC (2010) Assessing the power of informative subsets of loci for population assignment: standard methods are upwardly biased. Mol Ecol Resour 10:701-710

*Anderson EC, Waples RS, Kalinowski ST (2008) An improved method for predicting the accuracy of genetic stock identification. Can J Fish Aquat Sci 65:1475-1486

Araujo HA, Candy JR, Beacham TD, White B, Wallace C (2014) Advantages and challenges of genetic stock identification in fish stocks with low genetic resolution. Trans Am Fish Soc 143:479-488

Baird RW, Gorgone AM, McSweeney DJ, Ligon AD and others (2009) Population structure of island-associated dolphins: evidence from photo-identification of common bottlenose dolphins (Tursiops truncatus) in the main Hawaiian Islands. Mar Mamm Sci 25:251-274

Balmer BC, Wells RS, Nowacek SM, Nowacek DP and others (2008) Seasonal abundance and distribution patterns of common bottlenose dolphins (Tursiops truncatus) near St. Joseph Bay, Florida, USA. J Cetacean Res Manag 10: 157-167

Bassos-Hull K, Perrtree R, Shepard C, Schilling S and others (2013) Long-term site fidelity and seasonal abundance estimates of common bottlenose dolphins (Tursiops truncatus) along the southwest coast of Florida and responses to natural perturbations. J Cetacean Res Manag 13:19-30

Bossart GD (2011) Marine mammals as sentinel species for oceans and human health. Vet Pathol 48:676-690

Briski E, Ghabooli S, Bailey SA, MacIsaac HJ (2012) Invasion risk posed by macroinvertebrates transported in ships' ballast tanks. Biol Invasions 14:1843-1850

Copping A, Hanna L, Van Cleve B, Blake K, Anderson R (2015) Environmental Risk Evaluation System-an approach to ranking risk of ocean energy development on coastal and estuarine environments. Estuar Coasts 38(Suppl 1):287-302

Cornuet JM (1999) New methods employing multilocus genotypes to select or exclude populations as origins of individuals. Genetics 153:1989-2000

Crouch J, Shein K (2011) Prevailing winds - seasonal averages. In: Gulf of Mexico data atlas. National Coastal Data Development Center, Stennis Space Center, MS. www. ncddc.noaa.gov/website/DataAtlas/atlas.htm (accessed on 29 January 2016)

DWH NRDA (Deepwater Horizon Natural Resource Damage Assessment) Trustees (2016) Deepwater Horizon oil spill: final programmatic damage assessment and restoration plan and final programmatic environmental impact statement. www.gulfspillrestoration.noaa.gov/ restoration-planning/gulf-plan

Evanno G, Regnaut S, Goudet J (2005) Detecting the number of clusters of individuals using the software STRUCTURE: a simulation study. Mol Ecol 14:2611-2620

Excoffier L, Lischer HEL (2010) Arlequin suite ver 3.5: a new series of programs to perform population genetics analyses under Linux and Windows. Mol Ecol Resour 10: 564-567

Fazioli KL, Hofmann S, Wells RS (2006) Use of Gulf of Mexico coastal waters by distinct assemblages of bottlenose dolphins (Tursiops truncatus). Aquat Mamm 32:212-222

Gorgone A, Haase P, Griffith E, Hohn A (2008) Modeling response of target and nontarget dolphins to biopsy darting. J Wildl Manag 72:926-932

Gulland FMD, Hall AJ (2007) Is marine mammal health deteriorating? Trends in the global reporting of marine mammal disease. EcoHealth 4:135-150

Guo SW, Thompson EA (1992) Performing the exact test of Hardy-Weinberg proportion for multiple alleles. Biometrics 48:361-372

*Hall A, Law R, Wells D, Harwood J and others (1992) Organochlorine levels in common seals (Phoca vitulina) which were victims and survivors of the 1988 phocine distemper epizootic. Sci Total Environ 115:145-162

*Hammond JA, Hall AJ, Dyrynda EA (2005) Comparison of polychlorinated biphenyl (PCB) induced effects on innate immune functions in harbour and grey seals. Aquat Toxicol 74:126-138

*Hess JE, Whiteaker JM, Fryer JK, Narum SR (2014) Monitoring stock-specific abundance, run timing, and straying of chinook salmon in the Columbia River using genetic stock identification (GSI). N Am J Fish Manage 34: 184-201

Hiddink JG, Johnson AF, Kingham R, Hinz H (2011) Could our fisheries be more productive? Indirect negative effects of bottom trawl fisheries on fish condition. J Appl Ecol 48:1441-1449

*Hoelzel AR, Dahlheim M, Stern SJ (1998) Low genetic variation among killer whales Orcinus orca in the Eastern North Pacific and genetic differentiation between foraging specialists. J Hered 89:121-128

Holm S (1979) A simple sequentially rejective multiple test procedure. Scand J Stat 6:65-70

*Hubard CW, Maze-Foley K, Mullin KD, Schroeder WW (2004) Seasonal abundance and site fidelity of bottlenose dolphins (Tursiops truncatus) in Mississippi Sound. Aquat Mamm 30:299-310

* Ivashchenko YV, Clapham PJ (2014) Too much is never enough: the cautionary tale of Soviet illegal whaling. Mar Fish Rev 76:1-21

Kalinowski ST, Manlove KR, Taper ML (2007) ONCOR: a computer program for genetic stock identification. Montana State University, Bozeman, MT

Koljonen ML, Pella JJ, Masuda M (2005) Classical individ- 
ual assignments versus mixture modeling to estimate stock proportions in Atlantic salmon (Salmo salar) catches from DNA microsatellite data. Can J Fish Aquat Sci 62:2143-2158

Krützen M, Valsecchi E, Connor RC, Sherwin WB (2001) Characterization of microsatellite loci in Tursiops aduncus. Mol Ecol Notes 1:170-172

Kance SL, Love CN, Nunziata SO, O'Bryhim JR, Scott DE, Flynn RW, Jones KL (2013) 32 species validation of a new Illumina paired-end approach for the development of microsatellites. PLOS ONE 8:e81853

K Litz JA, Baran MA, Bowen-Stevens SR, Carmichael RH and others (2014) Review of historical unusual mortality events (UMEs) in the Gulf of Mexico (1990-2009): providing context for the multi-year northern Gulf of Mexico cetacean UME declared in 2010. Dis Aquat Org 112: 161-175

Manel S, Gaggiotti OE, Waples RS (2005) Assignment methods: matching biological questions with appropriate techniques. Trends Ecol Evol 20:136-142

Martien KK, Baird RW, Hedrick NM, Gorgone AM and others (2012) Population structure of island-associated dolphins: evidence from mitochondrial and microsatellite markers for common bottlenose dolphins (Tursiops truncatus) around the main Hawaiian Islands. Mar Mamm Sci 28:E208-E232

* McDonald TL, Hornsby FE, Speakman TR, Zolman ES and others (2017) Survival, density, and abundance of common bottlenose dolphins in Barataria Bay (USA) following the Deepwater Horizon oil spill. Endang Species Res 33:193-209

* Mengerink KJ, Van Dover CL, Ardron J, Baker M and others (2014) A call for deep-ocean stewardship. Science 344: 696-698

Moran P, Bromaghin JF, Masuda M (2014) Use of genetic data to infer population-specific ecological and phenotypic traits from mixed aggregations. PLOS ONE 9: e98470

Murawski SA (2010) Rebuilding depleted fish stocks: the good, the bad, and, mostly, the ugly. ICES J Mar Sci 67 : 1830-1840

NOAA (National Oceanic and Atmospheric Administration) (2013) The national coastal population report: populations trends from 1970 to 2020. NOAA State of the Coast Report Series. NOAA, Department of Commerce, and US Census Bureau. http://oceanservice.noaa.gov/facts/ coastal-population-report.pdf

Paetkau D, Slade R, Burden M, Estoup A (2004) Genetic assignment methods for the direct, real-time estimation of migration rate: a simulation-based exploration of accuracy and power. Mol Ecol 13:55-65

Park SDE (2001) Trypanotolerance in West African cattle and the population genetic effects of selection. PhD dissertation, University of Dublin

Peakall R, Smouse PE (2006) GENALEX 6: genetic analysis in Excel. Population genetic software for teaching and research. Mol Ecol Notes 6:288-295

* Peltier H, Dabin W, Daniel P, Van Canneyt O, Dorémus G, Huon M, Ridoux V (2012) The significance of stranding data as indicators of cetacean populations at sea: modelling the drift of cetacean carcasses. Ecol Indic 18:278-290

Piry S (2004) GeneClass2: a software for genetic assignment and first-generation migrant detection. J Hered 95: 536-539

* Pritchard JK, Stephens M, Donnelly P (2000) Inference of population structure using multilocus genotype data. Genetics 155:945-959

Pritchard JK, Wen X, Falush D (2009) Documentation for structure software: version 2.3. http://pritchardlab. stanford.edu/structure_software/release_versions/v2.3.4 /structure_doc.pdf

* Ramirez-Llodra E, Tyler PA, Baker MC, Bergstad OA and others (2011) Man and the last great wilderness: human impact on the deep sea. PLOS ONE 6:e22588

Rannala B, Mountain JL (1997) Detecting immigration by using multilocus genotypes. Proc Natl Acad Sci USA 94: 9197-9201

Reif JS (2011) Animal sentinels for environmental and public health. Public Health Rep 126:50-57

Kooney AP, Merritt DB, Derr JN (1999) Microsatellite diversity in captive bottlenose dolphins (Tursiops truncatus). J Hered 90:228-231

* Rosel PE, France SC, Wang JY, Kocher TD (1999) Genetic structure of harbour porpoise, Phocoena phocoena, populations in the Northwest Atlantic based on mitochondrial and nuclear markers. Mol Ecol 8:S41-S54

Kosel PE, Forgetta V, Dewar K (2005) Isolation and characterization of twelve polymorphic microsatellite markers in bottlenose dolphins (Tursiops truncatus). Mol Ecol Notes 5:830-833

Kosel PE, Hansen L, Hohn AA (2009) Restricted dispersal in a continuously distributed marine species: common bottlenose dolphins Tursiops truncatus in coastal waters of the western North Atlantic. Mol Ecol 18:5030-5045

* Rousset F (2008) GENEPOP'007: a complete re-implementation of the GENEPOP software for Windows and Linux. Mol Ecol Resour 8:103-106

Schwacke LH, Voit EO, Hansen LJ, Wells RS, Mitchum GB, Hohn AA, Fair PA (2002) Probabilistic risk assessment of the reproductive effects of polychlorinated biphenyls on bottlenose dolphins (Tursiops truncatus) from the southeast United States coast. Environ Toxicol Chem 21: 2752-2764

Schwacke LH, Zolman ES, Balmer BC, De Guise S and others (2012) Anaemia, hypothyroidism and immune suppression associated with polychlorinated biphenyl exposure in bottlenose dolphins (Tursiops truncatus). Proc R Soc B 279:48-57

Schwacke LH, Smith CR, Townsend FI, Wells RS and others (2014) Health of common bottlenose dolphins (Tursiops truncatus) in Barataria Bay, Louisiana, following the Deepwater Horizon oil spill. Environ Sci Technol 48: 93-103

Seeb LW, Habicht C, Templin WD, Tarbox KE, Davis RZ, Brannian LK, Seeb JE (2000) Genetic diversity of sockeye salmon of Cook Inlet, Alaska, and its application to management of populations affected by the Exxon Valdez oil spill. Trans Am Fish Soc 129:1223-1249

Seeb L, Antonovich A, Banks MA, Beacham T and others (2007) Development of a standardized DNA database for Chinook salmon. Fisheries (Bethesda, MD) 32:540-552

* Sellas AB, Wells RS, Rosel PE (2005) Mitochondrial and nuclear DNA analyses reveal fine scale geographic structure in bottlenose dolphins (Tursiops truncatus) in the Gulf of Mexico. Conserv Genet 6:715-728

Shane SH (1977) The population biology of the Atlantic bottlenose dolphin, Tursiops truncatus, in the Aransas Pass area of Texas. Master's thesis, Texas A\&M University, College Station, TX

Sinclair C, Sinclair J, Zolman E, Martinez A, Balmer B, Barry 
K (2015) Remote biopsy sampling field procedures for cetaceans used during the Natural Resource Damage Asessment of the MSC252 Deepwater Horizon oil spill. NOAA Tech Memo NMFS-SEFSC-670

Thomas L, Booth CG, Rosel PE, Hohn A, Litz J, Schwacke LH (2017) Where were they from? Modelling the source stock of dolphins stranded after the Deepwater Horizon oil spill using genetic and stable isotope data. Endang Species Res 33:253-264

United States Environmental Protection Agency (2012) National coastal condition report IV. EPA 842-R-10-003. Office of Research and Development and Office of Water, Washington, DC

Urian KW, Hofmann S, Wells RS, Read AJ (2009) Fine-scale population structure of bottlenose dolphins (Tursiops truncatus) in Tampa Bay, Florida. Mar Mamm Sci 25: 619-638

Valsecchi E, Amos W (1996) Microsatellite markers for the study of cetacean populations. Mol Ecol 5:151-156

*Van Oosterhout C, Hutchinson WF, Wills DPM, Shipley P (2004) Micro-checker: software for identifying and correcting genotyping errors in microsatellite data. Mol Ecol Notes 4:535-538

Venn-Watson S, Colegrove KM, Litz J, Kinsel M and others (2015) Adrenal gland and lung lesions in Gulf of Mexico common bottlenose dolphins (Tursiops truncatus) found dead following the Deepwater Horizon oil spill. PLOS ONE 10:e0126538

Vollmer NL (2011) Population structure of common bottlenose dolphins in coastal and offshore waters of the Gulf of Mexico revealed by genetic and environmental analysis. PhD dissertation, University of Louisiana at Lafayette

Vollmer NL, Rosel PE (2013) A review of common bottlenose dolphins (Tursiops truncatus truncatus) in the northern Gulf of Mexico: population biology, potential threats, and management. Southeast Nat 12:1-43

Editorial responsibility: Michael Moore (Guest Editor), Woods Hole, Massachusetts, USA
Waits LP, Luikart G, Taberlet P (2001) Estimating the probability of identity among genotypes in natural populations: cautions and guidelines. Mol Ecol 10:249-256

*Waples RS (2015) Testing for Hardy-Weinberg proportions: Have we lost the plot? J Hered 106:1-19

Waring GT, Josephson E, Maze-Foley K, Rosel PE (2015) U.S. Atlantic and Gulf of Mexico marine mammal stock assessments - 2014. NOAA Tech Memo NMFS-NE-231

*Weir BS, Cockerham CC (1984) Estimating F-statistics for the analysis of population structure. Evolution 38: 1358-1370

Wells RS, Scott MD, Irvine AB (1987) The social structure of free-ranging bottlenose dolphins. In: Genoways $\mathrm{H}$ (ed) Current mammalogy, Vol 1. Plenum Press, New York, NY, p 247-305

Wells RS, Rhinehart HL, Hansen LJ, Sweeney JC and others (2004) Bottlenose dolphins as marine ecosystem sentinels: developing a health monitoring system. EcoHealth $1: 246-254$

*Wells RS, Allen JB, Lovewell G, Gorzelany J, Delynn RE, Fauquier DA, Barros NB (2015) Carcass recovery rates for resident bottlenose dolphins in Sarasota Bay, Florida. Mar Mamm Sci 31:355-368

Wells RS, Schwacke LH, Rowles TK, Balmer BC and others (2017) Ranging patterns of common bottlenose dolphins Tursiops truncatus in Barataria Bay, Louisiana, following the Deepwater Horizon oil spill. Endang Species Res 33:159-180

Williams R, Gero S, Bejder L, Calambokidis J and others (2011) Underestimating the damage: interpreting cetacean carcass recoveries in the context of the Deepwater Horizon/BP incident. Conserv Lett 4:228-233

* Zavala Hidalgo J, Morey SL, O'Brien JJ (2003) Seasonal circulation on the western shelf of the Gulf of Mexico using a high resolution numerical model. J Geophys Res Oceans 108:3389

Submitted: March 17, 2016; Accepted: October 20, 2016 Proofs received from author(s): January 11, 2017 